\title{
The L-type calcium channel inhibitor diltiazem prevents cardiomyopathy in a mouse model
}

\author{
Christopher Semsarian, ${ }^{1}$ Imran Ahmad, ${ }^{1}$ Michael Giewat, ${ }^{1}$ Dimitrios Georgakopoulos, ${ }^{2}$ \\ Joachim P. Schmitt, ${ }^{1}$ Bradley K. McConnell, ${ }^{1}$ Steven Reiken, ${ }^{3}$ Ulrike Mende, ${ }^{4}$ \\ Andrew R. Marks, ${ }^{3}$ David A. Kass,${ }^{2}$ Christine E. Seidman, ${ }^{1,5}$ and J.G. Seidman ${ }^{1}$ \\ ${ }^{1}$ Department of Genetics, Howard Hughes Medical Institute and Harvard Medical School, Boston, Massachusetts, USA \\ ${ }^{2}$ Division of Cardiology, Department of Medicine, The Johns Hopkins Medical Institutions, Baltimore, Maryland, USA \\ ${ }^{3}$ Center for Molecular Cardiology, College of Physicians and Surgeons of Columbia University, New York, New York, USA \\ ${ }^{4}$ Cardiovascular Division, Brigham and Women's Hospital, Boston, Massachusetts, USA \\ ${ }^{5}$ Cardiovascular Division and Howard Hughes Medical Institute, Brigham and Women's Hospital, Boston, Massachusetts, USA \\ Address correspondence to: J.G. Seidman, Department of Genetics, Harvard Medical School, \\ 200 Longwood Avenue, Boston, Massachusetts 02115, USA. \\ Phone: (617) 432-7871; Fax: (617) 432-7832; E-mail: seidman@rascal.med.harvard.edu.
}

Received for publication November 20, 2001, and accepted in revised form March 11, 2002.

\begin{abstract}
Dominant mutations in sarcomere protein genes cause hypertrophic cardiomyopathy, an inherited human disorder with increased ventricular wall thickness, myocyte hypertrophy, and disarray. To understand the early consequences of mutant sarcomere proteins, we have studied mice (designated $\alpha M H C^{403 /+}$ ) bearing an Arg $403 \mathrm{Gln}$ missense mutation in the $\alpha$ cardiac myosin heavy chain. We demonstrate that $\mathrm{Ca}^{2+}$ is reduced in the sarcoplasmic reticulum of $\alpha M H C^{403 /+}$ mice, and levels of the sarcoplasmic reticulum $\mathrm{Ca}^{2+}$-binding protein calsequestrin are diminished in advance of changes in cardiac histology or morphology. Further evidence for dysregulation of sarcoplasmic reticulum $\mathrm{Ca}^{2+}$ in these animals is seen in their decreased expression of the ryanodine receptor $\mathrm{Ca}^{2+}$-release channel and its associated membrane proteins and in an increase in ryanodine receptor phosphorylation. Early administration of the L-type $\mathrm{Ca}^{2+}$ channel inhibitor diltiazem restores normal levels of these sarcoplasmic reticular proteins and prevents the development of pathology in $\alpha M H C^{403 /+}$ mice. We conclude that disruption of sarcoplasmic reticulum $\mathrm{Ca}^{2+}$ homeostasis is an important early event in the pathogenesis of this disorder and suggest that the use of $\mathrm{Ca}^{2+}$ channel blockers in advance of established clinical disease could prevent hypertrophic cardiomyopathy caused by sarcomere protein gene mutations.
\end{abstract}

J. Clin. Invest. 109:1013-1020 (2002). DOI:10.1172/JCI200214677.

\section{Introduction}

Hypertrophic cardiomyopathy is a prevalent autosomal dominant human disorder caused by mutations in contractile protein genes (for reviews, see refs. 1, 2). Over 200 DNA defects have been identified in ten disease genes that encode constituents of the cardiac muscle sarcomere. While much is known about these primary causes of hypertrophic cardiomyopathy, little is understood about the signaling events initiated by the mutant sarcomere that result in the hypertrophic response. Notably, there is a considerable latency period in the clinical expression of hypertrophic cardiomyopathy; ventricular hypertrophy evolves insidiously in genetically affected individuals, often beginning around pubescence. However, once established, the hypertrophic phenotype remains throughout life and causes a range of symptoms including chest pain, palpitations, and, in some, sudden death $(3,4)$. Sudden death can be the presenting manifestation of disease, and unrecognized hypertrophic cardiomyopathy remains the most frequent cause of sudden cardiac death in athletes $(5,6)$. Although a variety of pharmacologic agents are used to treat symptoms and arrhythmias in hypertrophic cardiomyopathy, therapies have not been identified that prevent expression of disease in individuals with sarcomere protein gene mutations. Study of animal models of hypertrophic cardiomyopathy (7-12) has indicated potential signaling pathways that may contribute to components of the cardiac pathology caused by sarcomere gene mutations. However, the identification of key early molecular events in disease pathogenesis has remained elusive. To define the early molecular steps in the pathogenesis of hypertrophic cardiomyopathy, $\alpha M H C^{403 /+}$ mice were studied. $\alpha M H C^{403 /+}$ mice carry an Arg403Gln missense mutation in one allele of the cardiac myosin heavy chain and model a severe human disease mutation (13). Like affected humans, $\alpha M H C^{403 /+}$ mice gradually develop myocardial hypertrophy, myocyte disarray, and fibrosis (14). Biochemical and biophysical studies indicate that $\alpha M H C^{403 /+}$ mice have abnormal $\mathrm{Ca}^{2+}$ homeostasis: myofibrillar preparations from mutant mice require higher $\mathrm{Ca}^{2+}$ concentrations to achieve the same contractile force as controls (15), and $\alpha M H C^{403 /+}$ mice treated with agents that affect myocyte $\mathrm{Ca}^{2+}$ levels exhibit dramatically accelerated hypertrophic pathology and decreased survival (16). Precise regulation of $\mathrm{Ca}^{2+}$ is essential for myocyte function (17). Cyclic fluxes of $\mathrm{Ca}^{2+}$ between three compartments - 
cytoplasm, sarcoplasmic reticulum (SR), and sarcomere account for excitation-contraction coupling. Depolarization triggers entry of small amounts of $\mathrm{Ca}^{2+}$ through the L-type $\mathrm{Ca}^{2+}$ channels located on the cell membrane, which in turn prompts $\mathrm{SR} \mathrm{Ca}^{2+}$ release by cardiac ryanodine receptors (RyR's), a process termed calcium-induced $\mathrm{Ca}^{2+}$ release. The resulting rapid rise in cytosolic levels fosters $\mathrm{Ca}^{2+}$-troponin-C interactions and triggers sarcomere contraction. Activation of the ATP-dependent calcium pump (SERCA) recycles cytosolic $\mathrm{Ca}^{2+}$ into the SR to restore sarcomere relaxation. To understand the mechanism by which calcium dysregulation occurs in $\alpha M H C^{403 /+}$ myocytes, we studied $\mathrm{Ca}^{2+}$-binding proteins in specific myocyte compartments and monitored the hypertrophic response to the Arg $403 \mathrm{Gln}$ missense mutation. We report that changes in $\mathrm{Ca}^{2+}$-binding protein levels occur in advance of disease, and we demonstrate that restoration of these protein levels by the L-type $\mathrm{Ca}^{2+}$ channel inhibitor diltiazem prevents clinical expression of hypertrophic cardiomyopathy in $\alpha M H C^{403 /+}$ mice.

\section{Methods}

Mice. $\alpha M H C^{403 /+}$ mice were generated as described (13) and were bred and maintained on the $129 / \mathrm{SvEv}$ genetic background. Selected mice were treated with diltiazem added to their drinking water $(450 \mathrm{mg} / \mathrm{l})$ corresponding to $1.8 \mathrm{mg}$ of diltiazem per day. Short-term studies involved treatment of mice with either enalapril, atenolol, or fludrocortisone added to their drinking water to achieve a dose of $25 \mathrm{mg} / \mathrm{kg} / \mathrm{d}$. All mice were maintained according to protocols approved by the Institutional Animal Care and Use Committee of Harvard Medical School. $R N A$ and protein analyses. Northern blot analyses were performed as described previously (14). Total RNA was isolated from the left ventricle using Trizol (GIBCO BRL; Life Technologies Inc., Carlsbad, California, USA) and analyzed by standard Northern blot procedures using oligonucleotide probes previously described (14). Myofibrillar-rich protein extracts were made from whole hearts using a high-salt extraction method as previously described $(18,19)$. In brief, isolated hearts were rapidly transferred to ice-cold extraction buffer containing 50 $\mathrm{mM} \mathrm{KH}_{2} \mathrm{PO}_{4}, 70 \mathrm{mM} \mathrm{NaF}, 5 \mathrm{mM}$ EDTA, and protease inhibitors. The samples were homogenized and centrifuged at $15,000 \mathrm{~g}$ for 10 minutes at $4^{\circ} \mathrm{C}$. The pellet was resuspended in extraction buffer containing $1 \%$ Triton $\mathrm{X}-100$ and centrifuged at $5,000 \mathrm{~g}$ for 5 minutes at room temperature. The resultant pellet was resuspended in extraction buffer and protein concentration determined. Samples were analyzed by standard Western blotting procedures (20). SR extracts were also prepared using differential centrifugation (21) and used for Western blot analyses. The following antibodies were used: rabbit polyclonal and mouse monoclonal anti-calsequestrin (both 1:1000; Affinity BioReagents Inc., Golden, Colorado, USA), mouse monoclonal anti-myosin (1:500; Biogenesis Ltd., Poole, United Kingdom), mouse monoclonal antitriadin (1:500; Affinity BioReagents Inc.), and mouse anti-RyR and rabbit anti-junctin antibodies (dilutions of
1:500 and 1:250, respectively; provided by L. Jones, Indiana University School of Medicine, Indianapolis, Indiana, USA). RNA and protein blots were quantitated by densitometry (NIH Image Analysis software, version 1.60).

Immunoprecipitation of RyR. Whole-cell homogenates were prepared as previously described (21). After determining the protein concentration, we aliquoted the supernatants and stored them at $-80^{\circ} \mathrm{C}$ until use. Ryanodine receptor-2 (RyR2) was immunoprecipitated from cardiac samples by incubating $500 \mathrm{mg}$ of homogenate with antiRyR antibody in $0.5 \mathrm{ml}$ of a modified radioimmunoprecipitation buffer ( $50 \mathrm{mM}$ Tris- $\mathrm{HCl}[\mathrm{pH} 7.4], 0.9 \% \mathrm{NaCl}, 1.0$ $\mathrm{mM} \mathrm{NaF}, 1.0 \mathrm{mM} \mathrm{Na}_{3} \mathrm{PO}_{4}, 0.25 \%$ Triton X-100, and protease inhibitors) overnight at $4^{\circ} \mathrm{C}$. Protein A-Sepharose beads were added, incubated at $4^{\circ} \mathrm{C}$ for 1 hour. Immunoprecipitated proteins were separated by PAGE and analyzed for RyR2 and FKBP12.6 by immunoblotting.

Back-phosphorylation of RyR2. RyR2 was immunoprecipitated from cardiac homogenates as described above. The protein $A$ beads were washed with $1 \times$ phosphorylation buffer $(8 \mathrm{mM} \mathrm{MgCl} 2,10 \mathrm{mM}$ EGTA, and $50 \mathrm{mM}$ Tris/PIPES, pH 6.8), and resuspended in $10 \mathrm{ml}$ of a $1.5 \times$ phosphorylation buffer containing either protein kinase A (PKA) catalytic subunit (Sigma Aldrich Co., St. Louis, Missouri, USA) or PKA plus a PKA inhibitor (PKI5-24, $500 \mathrm{nM}$; Calbiochem-Novabiochem Corp., San Diego, California, USA). Back-phosphorylation of immunoprecipitated RyR2 was initiated with $33 \mu \mathrm{M} \mathrm{Mg}$-ATP containing 10\% [ $\left.\gamma^{-32} \mathrm{P}\right] \mathrm{ATP}$ (NEN Life Sciences, Boston, Massachusetts, USA) and terminated after 5 minutes at room temperature with $5 \mathrm{ml}$ of stop solution (4\% SDS and $0.25 \mathrm{M} \mathrm{DTT}$ ). Samples were heated to $95^{\circ} \mathrm{C}$ and size-fractionated on 6\% SDS-PAGE, and RyR2 radioactivity was quantified using a PhosphorImager (Molecular Dynamics, Sunnyvale, California, USA) and ImageQuant software (Amersham Pharmacia Biotech, Piscataway, New Jersey, USA). Nonspecific phosphorylation (not inhibited by PKA inhibitor) was subtracted, and the resulting value was divided by the amount of RyR2 protein (determined by immunoblotting and densitometry) and expressed as the inverse of the PKAdependent $\left[\gamma^{-32} \mathrm{P}\right]$ ATP signal.

Histopathology. Cardiac tissue was treated for histologic and morphologic examination as described $(13,14)$. In brief, the heart was excised from wild-type and $\alpha M H C^{403 /+}$ mice, washed in $37^{\circ} \mathrm{C}$ Dulbecco's PBS, and arrested in $50 \mathrm{mM} \mathrm{KCl}$. Sections from fixed, embedded tissues were stained with either hematoxylin and eosin or Masson's Trichrome. The amount of fibrosis was quantitated using IP Lab Scientific Imaging Software (version 3.5; Scanalytics Inc., Fairfax, Virginia, USA).

Mouse echocardiography. Echocardiographic studies were performed on mice using a 6- to $15-\mathrm{MHz}$ linear array probe with a Sonos 4500 ultrasonograph (HewlettPackard, Andover, Massachusetts, USA) as described (14, 16). Mice were anesthetized with $2.5 \%$ tribromoethanol $(0.010 \mathrm{ml} / \mathrm{g})$, warmed with a heating pad, and attached to an ECG monitor. Left ventricular end-diastolic (LVDD) and end-systolic (LVSD) chamber dimensions 
and wall thickness were obtained from M-mode tracings using measurements averaged from three separate cardiac cycles. Left ventricular fractional shortening (\%) was derived as follows: (LVDD - LVSD)/LVDD $\times 100$. A single observer, who did not know the mouse's genotype, made all echocardiographic measurements. Heart rates were determined from electrocardiographic recordings performed during echocardiography.

Cardiac hemodynamics. Left ventricular hemodynamic studies were performed in mice as described previously (22). In brief, anesthetized mice were intubated and artificially ventilated, and real-time left ventricular pressure-volume relationships were measured using a newly developed miniaturized impedance/micromanometer catheter (Millar Instruments Inc., Houston, Texas, USA). Aortic flow was measured by an ultrasound perivascular probe (Transonic Systems Inc., Ithaca, New York, USA) placed around the thoracic aorta. Pressurevolume signals were recorded at steady-state and during transient reduction of cardiac preload achieved by occlusion of the inferior vena cava. Data were digitized at $2 \mathrm{kHz}$ for subsequent analysis.

Electrocardiogram telemetry. Electrocardiograms (ECGs) were recorded telemetrically in conscious, freely moving mice by monitoring signals from surgically implanted transmitters (model ETA-F20; Data Sciences International, St. Paul, Minnesota, USA). Studies on wild-type and $\alpha M H C^{403 /+}$ age- and sex-matched mice in a $129 / \mathrm{SvEv}$ genetic background were started 48 hours after completion of surgery. Receiver plates and analogue ECG adapters (Data Sciences International) were used to collect data into a MacLab charts program (ADInstruments, Grand Junction, Colorado, USA).

Mouse myocyte preparation and $\mathrm{Ca}^{2+}$ measurements. Isolated adult myocytes were prepared as described (16) with minor modifications. Hearts were digested with collagenase type I $(230 \mathrm{U} / \mathrm{ml}$; Worthington Biochemical Corp., Lakewood, New Jersey, USA) in physiological buffer containing (in mM): $126 \mathrm{NaCl}, 4.4 \mathrm{KCl}, 1 \mathrm{MgCl}_{2}, 4 \mathrm{NaHCO}_{3}$, 10 HEPES, 11 glucose, $\mathrm{pH} 7.35$, supplemented with 25 $\mu \mathrm{M} \mathrm{CaCl}{ }_{2}$ and $30 \mathrm{mM}$ 2,3-butanedione (BDM). The released myocytes from both ventricles were gradually subjected to increased calcium and decreased BDM concentrations. Cells were loaded with the fluorescent $\mathrm{Ca}^{2+}$ indicator fura-2 $(1 \mathrm{mM})$, and fluorescence was measured using a dual-excitation fluorescence imaging/contractility recording system (IonOptix Corp., Milton, Massachusetts, USA) according to established procedures (16). Caffeine was administered at a dose of $10 \mathrm{mM}$ to produce $\mathrm{Ca}^{2+}$ release from the SR; maximum fluorescence was used as a measure of $\mathrm{SR} \mathrm{Ca}^{2+}(23)$.

Immunohistochemistry. Immunostaining was performed in isolated adult myocytes, which were allowed to settle on polyglycine coverslips and fixed with methanol at $-20^{\circ} \mathrm{C}$. Calsequestrin primary antibodies used were the same as for Western blotting at a dilution of 1:500 for both. Mouse anti-myosin antibody (Biogenesis Ltd.) was used at a dilution of 1:200. Fluorophore-labeled (Alexa Fluor 488; Molecular Probes Inc., Eugene, Oregon, USA) secondary antibodies at a dilution of 1:500-1:1000 were used for calsequestrin; a rhodamine (red-labeled) secondary antibody at a dilution of 1:200 was used for myosin. Immunostained myocytes were analyzed by both compound and confocal microscopy.

Statistical analysis. The statistical significance of differences between groups of wild-type and $\alpha M H C^{403 /+}$ mice in continuous variables was determined by unpaired Student $t$ test and ANOVA for determination of drug and genotype effects. Data are expressed as mean \pm SD. A $P$ value less than 0.05 was considered significant.

\section{Results}

Attenuated $\mathrm{Ca}^{2+}$ responses were previously observed in $\alpha M H C^{403 /+}$ mice treated with two pharmacologically distinct agents, cyclosporin $\mathrm{A}$ and minoxidil (16). The hypothesis was therefore made that this deficient response indicated decreased $\mathrm{SR} \mathrm{Ca}^{2+}$ stores caused by the sarcomere gene mutation. To test this hypothesis, isolated cardiac myocytes from wild-type and untreated $\alpha M H C^{403 /+}$ mice were fura-2-loaded and exposed to caffeine, which promotes $\mathrm{SR} \mathrm{Ca}^{2+}$ release via RyR2. The amount of cytosolic $\mathrm{Ca}^{2+}$ was monitored by emission of fluorescence at specified wavelengths. A 10-mM caffeine bolus produced prompt and significant $\mathrm{Ca}^{2+}$ release into

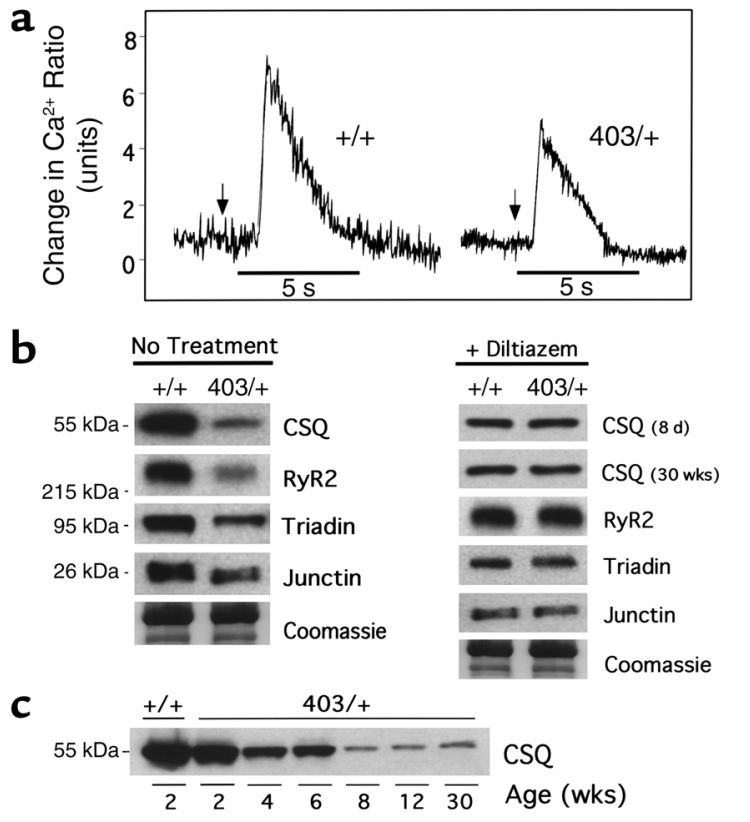

Figure 1

SR Ca ${ }^{2+}$ storage and altered $\mathrm{Ca}^{2+}$-related protein expression. (a) $\mathrm{Ca}^{2+}$ changes, assessed in wild-type $\left(^{+/+}\right)$and $\alpha \mathrm{MHC}^{403 /+}(403 /+)$ myocytes, in response to a bolus administration of $10 \mathrm{mM}$ caffeine (vertical arrows indicate time of administration). (b) Western blot analysis of calsequestrin (CSQ) and components of the quaternary complex in myofibrillar protein extracts from wild-type and $\alpha \mathrm{MHC}^{403 /+}$ mice aged $30-50$ weeks. Coomassie staining indicates loading of samples in each lane. Treatment of $\alpha \mathrm{MHC}^{403 /+}$ mice with diltiazem led to normalization of all four components of the RyR2 complex - calsequestrin ( 8 days treatment), triadin, junctin, and RyR2 (30 weeks treatment). (c) Time course study of changes in calsequestrin protein expression in equal amounts of myofibrillar extracts from mice aged 2, 4, 6, 8, 12, and 30 weeks. 

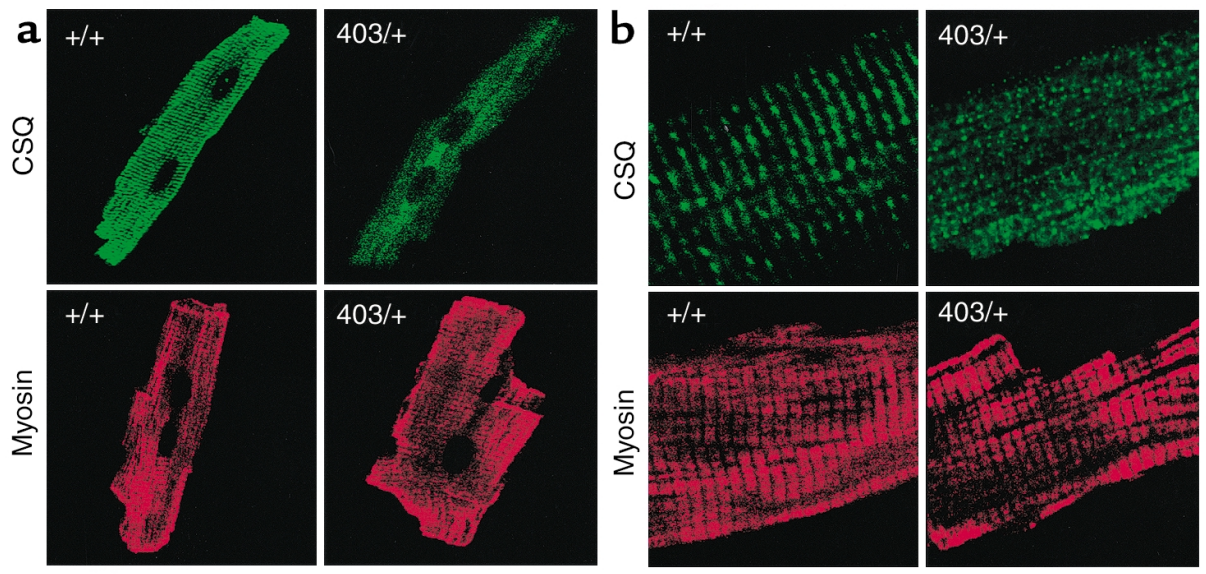

Figure 2

Calsequestrin localization within myocytes. (a) Immunostaining of isolated wild-type $(+/+)$ and $\alpha \mathrm{MHC}^{403 /+}$ $(403 /+)$ myocytes with calsequestrin (CSQ) and myosin primary antibodies. Calsequestrin primary antibodies were detected with a fluoro-conjugated secondary antibody, and myosin antibodies were visualized with a rhodaminered secondary antibody (confocal images at $\times 40$ magnification). (b) Corresponding images analyzed at higher magnification $(\times 200)$, demonstrating loss of normal distribution of calsequestrin within $\alpha \mathrm{MHC}^{403 /+}$ myocytes. cytoplasm from wild-type myocytes (maximum height $=$ $158.8 \pm 55$ units; $n=28$ ) but a smaller response (maximum height $=133.1 \pm 41$ units; $n=25)$ from $\alpha M H C^{403 /+}$ myocytes (Figure 1a and data not shown; $P=0.007$ ). These data suggest that the SRs of wild-type myocytes contain more $\mathrm{Ca}^{2+}$ than do those of mutant myocytes. $\mathrm{Ca}^{2+}$-binding proteins from whole-cell preparations, myofibrillar extracts, and SR extracts were assessed by Western blot analysis. Several proteins were specifically reduced in myofibrillar extracts from mutant myocytes as compared with wild-type extracts. The amounts of calmodulin, calcineurin (PP2B-A $\alpha$ and -A $\beta$ ), SERCA2, and phospholamban in myofibrillar extracts were comparable in wild-type and $\alpha M H C^{403 /+}$ myocytes (data not shown). However, calsequestrin, the primary $\mathrm{Ca}^{2+}$ storage protein in the SR, was markedly reduced in myofibrillar preparations and SR extracts of $\alpha M H \mathrm{C}^{403 /+}$ ventricles. A $56 \% \pm 19 \%$ reduction of normal calsequestrin levels was observed in myofibrillar preparations $(n=8)$ from mutant mice (Figure 1b). Comparable low calsequestrin levels were observed in 15- to 20-week-old and 30 - to 50-week-old $\alpha M H C^{403 /+}$ mice (data not shown).
Calsequestrin protein levels were then examined in younger $\alpha M H \mathrm{C}^{403 /+}$ mice. Although calsequestrin levels in myofibrillar extracts from neonates and 2-week-old mutant mice (Figure 1c) were comparable to levels found in wild-type mice, calsequestrin was decreased in extracts from 4-week-old mutant mice. This decrease in calsequestrin level paralleled the augmented expression of the mutant $\alpha$ isoform of cardiac myosin heavy chain, which occurs 1-2 weeks after birth (24). Notably, this timeline precedes the onset of left ventricular hypertrophy by many weeks $(14,25)$. These data indicate that changes in calsequestrin levels are an early molecular event in the pathogenesis of hypertrophic cardiomyopathy.

Calsequestrin forms a quaternary complex in the SR membrane, with the cardiac RyR2 channel and two other membrane proteins, junctin and triadin (26). Levels of these proteins were examined by Western blotting. Each of these components was significantly decreased in myofibrillar preparations from the SR of $\alpha M H C^{403 /+}$ myocytes compared with wild-type cells (Figure 1b; decrease of $63 \% \pm 20 \%, 48 \% \pm 4 \%$, and $38 \% \pm 5 \%$ for RyR2, triadin, and junctin respectively; $n=3$ in each group;

Table 1

Left ventricular function of wild-type and $\alpha \mathrm{MHC}^{403 /+}$ mice aged $30-50$ weeks with or without diltiazem treatment

\begin{tabular}{|c|c|c|c|c|c|c|}
\hline \multirow[b]{2}{*}{ Parameter } & \multicolumn{2}{|c|}{ No treatment } & \multicolumn{2}{|c|}{ Diltiazem-treated } & \multicolumn{2}{|c|}{ Statistics } \\
\hline & WT & $\alpha M H C^{403 /+}$ & WT & $\alpha M H C^{403 /+}$ & ANOVA & $t$ test \\
\hline Number of mice & 5 & 5 & 3 & 5 & $P$ value & $P$ value \\
\hline Heart rate (bpm) & $627 \pm 48$ & $641 \pm 34$ & $600 \pm 34$ & $576 \pm 12$ & NS & 0.0018 \\
\hline \multicolumn{7}{|l|}{ Systolic } \\
\hline $\begin{array}{l}\operatorname{ESV}(\mu \mathrm{l}) \\
\operatorname{EDV}(\mu \mathrm{l}) \\
\operatorname{EF}(\%) \\
\operatorname{EES}(\mathrm{mmHg} / \mu \mathrm{l}) \\
\mathrm{dP} / \mathrm{dt}_{\max }(\mathrm{mmHg} / \mathrm{s})\end{array}$ & $\begin{aligned} 6.3 & \pm 2.2 \\
27.3 & \pm 7.8 \\
74.6 & \pm 15.4 \\
16.8 & \pm 4.3 \\
15,967 & \pm 1,952\end{aligned}$ & $\begin{aligned} 2.5 & \pm 1.6 \\
16.0 & \pm 6.5 \\
81.8 & \pm 14.6 \\
50.4 & \pm 6.4 \\
20,862 & \pm 2,407\end{aligned}$ & $\begin{aligned} 13.6 & \pm 4.9 \\
35.3 & \pm 3.1 \\
62.3 & \pm 10.4 \\
3.07 & \pm 0.5 \\
14,291 & \pm 510\end{aligned}$ & $\begin{aligned} 17.7 & \pm 5.2 \\
40.0 & \pm 4.3 \\
56.4 & \pm 9.6 \\
3.67 & \pm 3.5 \\
14,862 & \pm 1048\end{aligned}$ & $\begin{array}{c}0.006 \\
0.017 \\
\text { NS } \\
<0.001 \\
0.023\end{array}$ & $\begin{aligned}< & 0.001 \\
< & 0.001 \\
& 0.010 \\
< & 0.001 \\
< & 0.001\end{aligned}$ \\
\hline \multicolumn{7}{|l|}{ Diastolic } \\
\hline $\begin{array}{l}\mathrm{dP} / \mathrm{dt}_{\min }(\mathrm{mmHg} / \mathrm{s}) \\
\beta \\
\text { tau } g(\mathrm{~ms}) \\
\text { Pressure }_{1 / 2} \text { time }(\mathrm{mmHg})\end{array}$ & $\begin{aligned}-14,087 & \pm 6,231 \\
0.029 & \pm 0.007 \\
7.36 & \pm 1.5 \\
3.97 & \pm 0.66\end{aligned}$ & $\begin{aligned}-9,879 & \pm 1,400 \\
0.118 & \pm 0.060 \\
12.3 & \pm 3.3 \\
5.04 & \pm 0.85\end{aligned}$ & $\begin{aligned}-14,555 & \pm 661 \\
0.130 & \pm 0.063 \\
7.54 & \pm 0.42 \\
4.04 & \pm 0.14\end{aligned}$ & $\begin{aligned}-10,290 & \pm 661 \\
0.122 & \pm 0.021 \\
11.7 & \pm 0.22 \\
6.00 & \pm 0.16\end{aligned}$ & $\begin{array}{l}\text { NS } \\
0.011 \\
\text { NS } \\
\text { NS }\end{array}$ & $\begin{array}{c}\text { NS } \\
\text { NS } \\
\text { NS } \\
0.0380\end{array}$ \\
\hline
\end{tabular}

Parameters are grouped into measures of systolic (contractile) and diastolic (relaxation). WT, wild-type; bpm, beats per minute; ESV, end-systolic volume; EDV, end-diastolic volume; EF, ejection fraction; EES, elastance end-systolic; $\beta$, diastolic stiffness; tau g, tau Glantz; NS, not significant. ANOVA assesses drug and genotype effects; unpaired $t$ test compares $\alpha M H C^{403 /+}$ mice with and without diltiazem treatment. $\mathrm{dP} / \mathrm{dt}_{\max }$, maximal change in pressure over change in time. 
$P<0.001$ vs. wild-type). RyR2 channel phosphorylation was also assessed. (RyR2 was also decreased in SR extracts from $\alpha M H C^{403 /+}$ hearts; data not shown.) PKA phosphorylation of the RyR2 channel was increased almost threefold in SR preparations from $\alpha M H C^{403 /+}$ mouse hearts compared with wild-type ( $2.8 \pm 0.2$ units vs. $1.0 \pm 0.1$ units in wild-type; $n=3$ in each group; $P<0.001)$. Consistent with the PKA hyperphosphorylation of RyR2 channels, coimmunoprecipitation assays showed that the amount of FKBP12.6 bound to the RyR 2 channel was reduced by $40 \%(0.6 \pm 0.1$ units vs. $1.0 \pm 0.1$ units in wild-type; $n=3$ in each group; $P<0.001)$. Collectively these data indicate that the RyR 2 channels are both reduced in number and functionally modified in $\alpha M H C^{403 /+}$ mice, such that the sensitivity of the channels to $\mathrm{Ca}^{2+}$ and the channels' gating properties are altered.

To further evaluate SR binding proteins in $\alpha M H C^{403 /+}$ myocytes, immunohistochemical studies were performed. In wild-type myocytes, antibody-labeled SR calsequestrin exists in close association with the sarcomere (27) (Figure 2a). Immunocytochemistry of calsequestrin, like myosin and other sarcomere proteins, exhibited a highly registered pattern of cross-striations, demarcated by the two nuclei characteristic of cardiac myocytes (Figure 2 , a and b). $\alpha M H C^{403 /+}$ myocytes are more irregularly shaped than wild-type cells and exhibited a nonuniform pattern of calsequestrin immunohistochemistry (Figure 2a). The normal alignment of calsequestrin along sarcomere cross-striations observed in wild-type cardiac myocytes was observed in approximately half of $\alpha M H C^{403 /+}$ myocytes (data not shown). The remaining $\alpha M H C^{403 /+}$ myocytes demonstrated no association between calsequestrin and sarcomere cross-striations, despite having normal sarcomere structure based on normal sarcomeric patterns with myosin (Figure 2, a and b) and actin antibodies (data not shown). High-power magnification of $\alpha M H C^{403 /+}$ myocytes confirmed a disordered alignment of SR calsequestrin but did not show sarcomere disarray: cross-striations of the myosin-decorated sarcomere appeared normal in $\alpha M H C^{403 /+}$ myocytes (Figure 2, a and b). Together with the reduction of calsequestrin levels in myofibrillar extracts, this indicates that both structural and functional alteration of SR $\mathrm{Ca}^{2+}$ binding proteins occurs in $\alpha M H \mathrm{C}^{403 /+}$ myocytes.

In an attempt to correct aberrant $\mathrm{Ca}^{2+}$ handling in $\alpha M H C^{403 /+}$ myocytes, several pharmacologic agents were administered. Diltiazem, an L-type $\mathrm{Ca}^{2+}$ channel inhibitor; atenolol, a $\beta$-adrenergic inhibitor; enalapril, an angiotensin-converting enzyme inhibitor; and fludrocortisone, a mineralocorticoid that alters cardiac volume, were orally administered (see Methods) to young (age 6-8 weeks) male wild-type and $\alpha M H C^{403 /+}$ mice ( $n=6$ in diltiazem treatment group; $n=2$ each for other three agents) for 7-10 days. In addition to specific effects of each drug, these pharmacologic agents alter cardiac hemodynamics. Both diltiazem and atenolol decrease heart rate; these and enalapril can also reduce blood pressure. Fludrocortisone can alter circulatory volume. Only the L-type $\mathrm{Ca}^{2+}$ channel inhibitor diltiazem affected levels of the calsequestrin complex in mutant mice, suggesting that the effect of diltiazem was independent of its effects on heart rate or blood pressure. Levels of calsequestrin, triadin, junctin, and RyR2 from myofibrillar extracts of diltiazem-treated $\alpha M H C^{403 /+}$ mice were higher than those of untreated $\alpha M H C^{403 /+}$ extracts (Figure $1 \mathrm{~b}$ ) and comparable to levels found in myofibrillar extracts from wild-type mice. Diltiazem restoration of calsequestrin levels was brisk, occurring within 8 days of treatment, and sustained during 30 weeks of treatment (Figure 1b). Furthermore, the amount of $\mathrm{Ca}^{2+}$ in the SR of myocytes, as measured by caffeine release (23), from diltiazem-treated wild-type and mutant hearts was not different $(n=16$ wild-type myocytes and 29 mutant myocytes; $P=0.23$ ).

Previous studies had demonstrated that diltiazem abrogated the accelerated and exaggerated hypertrophic response of $\alpha M H C^{403 /+}$ mice to cyclosporin A and minoxidil (16). To ascertain the effects of diltiazem on the natural progression of disease, this calcium channel inhibitor was orally administered to male, prehypertrophic $\alpha M H C^{403 /+}$ mice $(n=8$ wild-type and 12 $\left.\alpha M H C^{403 /+}\right)$ for 30 weeks. No differences were observed between treatment initiated in mice of age 6-8 weeks
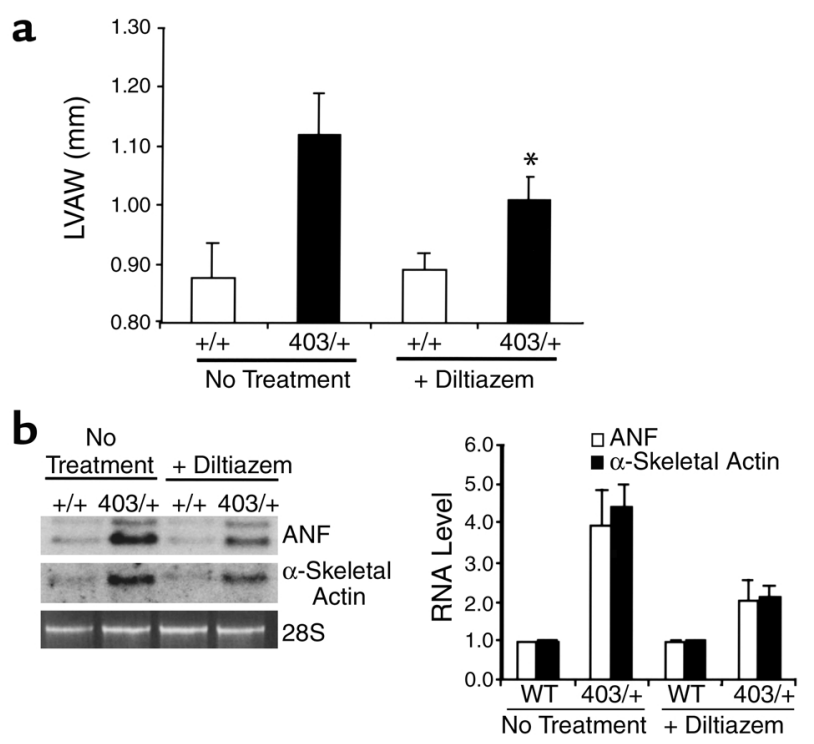

\section{Figure 3}

Prevention of cardiac hypertrophy in $\alpha \mathrm{MHC}^{403 /+}$ mice. (a) Left ventricular anterior wall thickness (LVAW) was evaluated in wild-type and $\alpha \mathrm{MHC}^{403 /+}$ mice at 30-50 weeks of age using transthoracic echocardiography. A left ventricular anterior wall thickness greater than 1.00 $\mathrm{mm}$, in mice 30-50 weeks of age, is considered to be hypertrophied. White bars indicate wild-type mice; black bars represent $\alpha M H C^{403 /+}$ mice. ${ }^{*} P<0.01$ vs. untreated $\alpha M H C^{403 /+}$ mice. Two mice (one wildtype, one $\alpha \mathrm{MHC}^{403 /+}$ mouse) died during the study and were not included in the analysis. (b) Changes in RNA molecular markers of cardiac hypertrophy. RNA expression in hearts from $\alpha \mathrm{MHC}^{403 /+}$ mice (30-50 weeks old) compared with expression in age-matched wildtype (WT) hearts, with and without diltiazem treatment. Northern blots of atrial natriuretic factor (ANF) and $\alpha$-skeletal actin expression are shown. RNA levels were standardized to 28S RNA band stained with ethidium bromide. The intensity of hybridizing species was assessed by densitometry of the Northern blots, and the RNA levels were normalized to the ANF level in wild-type left ventricle. 
a
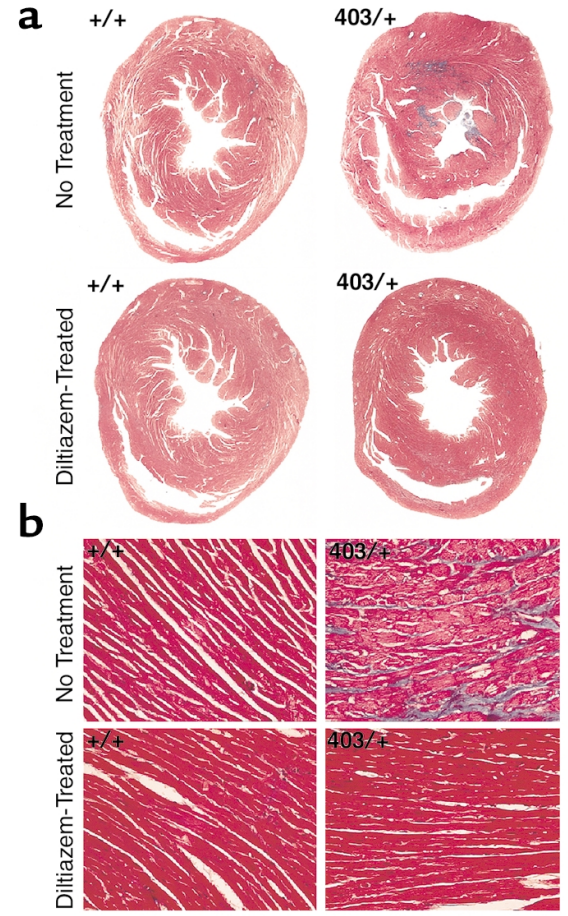

\section{Figure 4}

Histopathologic analyses of diltiazem-treated mice. (a) Low-magnification $(\times 2.5)$ images of whole-heart sections from wild-type and $\alpha M H C^{403 /+}$ mice cut transversely through the left and right ventricles, and stained with Masson's Trichrome. Areas of fibrosis (blue) are seen in $\alpha M H C^{403 /+}$ hearts that are absent in diltiazem-treated hearts. (b) High-magnification $(\times 100)$ images of left ventricular sections, stained with Masson's Trichrome. Myocyte hypertrophy, disarray, and fibrosis are present in untreated $\alpha \mathrm{MHC}^{403 /+}$ hearts; all changes are prevented with diltiazem treatment.

and in mice of age 10-12 weeks. Cardiac hemodynamics were profiled in diltiazem-treated wild-type and $\alpha M H C^{403 /+}$ mice. ECG telemetry demonstrated a $13.4 \%$ reduction in heart rates of both wild-type and mutant unanesthetized mice $(582 \pm 25$ beats per minute in untreated vs. $504 \pm 1$ beats per minute in diltiazem-treated; $P<0.05)$. Diltiazem did not change atrioventricular (PR interval) or intraventricular (QRS) conduction as compared with untreated mice, and no ventricular arrhythmias were observed (data not shown). Tail-cuff blood pressure measurements $(n>20)$ were compared in four conscious treated and untreated mutant mice; no differences were found in the mean systolic blood pressure (treated, $121 \pm 6 \mathrm{mmHg}$; untreated, $120 \pm 7 \mathrm{mmHg}$ ).

Invasive cardiac hemodynamic monitoring in diltiazem-treated $\alpha M H C^{403 /+}$ mice demonstrated improvements in contractile (systolic) properties. Increases in end-diastolic and end-systolic volumes compared with untreated $\alpha M H C^{403 /+}$ mice were observed, indicating overall improved cardiac function (Table 1). Maximal change in pressure over change in time $\left(\mathrm{dP} / \mathrm{dt}_{\max }\right)$ values and end-systolic elastance (EES) also indicated enhanced ventricular contraction with diltiazem $\left(P<0.001\right.$ vs. untreated $\alpha M H C^{403 /+}$ mice $)$. Measures of ventricular relaxation, e.g., time to peak filling,
$\mathrm{dP} / \mathrm{dt}_{\min }$, and tau, were unchanged in diltiazem-treated compared with untreated $\alpha M H C^{403 /+}$ mice.

Ventricular hypertrophy is demonstrable by twodimensional echocardiogram at 30 weeks in $\alpha M H C^{403 /+}$ mice $(14,25)$. We performed echocardiography in diltiazem-treated wild-type and $\alpha M H C^{403 /+}$ mice at ages 30 and 39 weeks and compared left ventricular wall measurements in untreated age-, sex-, and strain-matched wild-type and $\alpha M H C^{403 /+}$ mice ( $n=23$ total untreated). Ventricular chamber volumes, left atrial dimensions, and fractional shortening in $\alpha M H C^{403 /+}$ mice were not affected by diltiazem treatment (data not shown). Left ventricular wall thickness of wild-type mice was not affected by diltiazem treatment $(0.89 \pm 0.03$ vs. $0.87 \pm 0.06 \mathrm{~mm}$ in untreated; $P=$ not significant; Figure $3 \mathrm{a}$ ). In contrast, the maximum left ventricular wall thickness of diltiazem-treated $\alpha M H C^{403 /+}$ mice was significantly less than that of untreated age-matched $\alpha M H C^{403 /+}$ mice at 30 weeks and at 39 weeks $(1.01 \pm 0.05$ vs. $1.12 \pm 0.07 \mathrm{~mm}$; $P<0.001$; Figure 3a). Wall thickness reduction was seen uniformly throughout the left ventricle, with comparable diminution of anterior and posterior left ventricular wall hypertrophy. Molecular markers of cardiac hypertrophy were also assessed. Untreated adult $\alpha M H C^{403 /+}$ mice had a three- to fivefold increase in RNA expression of atrial natriuretic factor (ANF) and $\alpha$-skeletal actin compared with wild-type mice (Figure $3 \mathrm{~b}$ ). In contrast, diltiazem-treated $\alpha M H C^{403 /+}$ mice had approximately $50 \%$ less ANF and $\alpha$-skeletal actin RNA expression (Figure $3 \mathrm{~b}$ ) than untreated mutant mice.

The pathologic hallmarks of hypertrophic cardiomyopathy - myocyte hypertrophy, disarray, and fibrosis - were also assessed in diltiazem-treated mice. Thirtyweek-old untreated $\alpha M H C^{403 /+}$ mice demonstrate typical histopathology of hypertrophic cardiomyopathy $(13,14)$. Sections that were reacted with Masson's Trichrome stain exhibited significant fibrosis (Figure 4a). The fractional area of myocardium that reacted with Masson's Trichrome stain was compared in histologic sections from diltiazem-treated and untreated $\alpha M H C^{403 /+}$ hearts (Figure 4a). Twenty pathologic sections were analyzed from ten anatomic levels in the left ventricles of hearts. Whereas $4.07 \% \pm 0.18 \%$ of the left ventricle was fibrotic in untreated $\alpha M H C^{403 /+}$ hearts $(n=3)$, significantly less fibrosis $(0.23 \% \pm 0.04 \%)$ was present in diltiazem-treated $\alpha M H C^{403 /+}$ hearts $(n=4$; $P<0.001$ vs. untreated $\alpha M H C^{403 /+}$ mice). Comparison of hematoxylin and eosin-stained myocardial sections also revealed less myocyte hypertrophy and disarray in 30 -week-old diltiazem-treated than in untreated $\alpha M H C^{403 /+}$ mice (Figure $4 \mathrm{~b}$ ).

\section{Discussion}

This study demonstrates that abnormal $\mathrm{SR} \mathrm{Ca}^{2+}$ responses and reduced $\mathrm{Ca}^{2+}$-binding proteins are early events in the pathogenesis of hypertrophic cardiomyopathy in $\alpha \mathrm{MHC}^{403 /+}$ mice. Caffeine-induced release of $\mathrm{SR} \mathrm{Ca}^{2+}$ stores and levels of calsequestrin, the $\mathrm{Ca}^{2+}$ channel RyR2, and associated peptides junctin and triadin 
were decreased in advance of histopathology or echocardiographic evidence of cardiac hypertrophy in $\alpha M H C^{403 /+}$ mice. Restitution of normal $\mathrm{Ca}^{2+}$ storage protein levels occurred in response to diltiazem-mediated inhibition of L-type $\mathrm{Ca}^{2+}$ channels, and when diltiazem was administered early to $\alpha M H C^{403 /+}$ mice, the cardiac histopathology and hemodynamic features of this sarcomere protein mutation were significantly abated.

Previous studies demonstrated that levels of cytosolic $\mathrm{Ca}^{2+}$ in $\alpha M H C^{403 /+}$ myocytes are comparable to those found in wild-type cells (16). However, responses to pharmacologic agents such as cyclosporin A or minoxidil, which produce a brisk $(30 \%)$ increase in diastolic $\mathrm{Ca}^{2+}$ levels in wild-type myocytes, are attenuated $(<8 \%$ increases) in $\alpha M H C^{403 /+}$ myocytes (16). This diminutive response by $\alpha M H C^{403 /+}$ myocytes is explained by the current studies. In response to the potent activation of RyR2 channels by caffeine, the maximum and total $\mathrm{Ca}^{2+}$ release from the SR was less in $\alpha M H C^{403 /+}$ myocytes than in wild-type myocytes. This suggests that the SRs of $\alpha M H C^{403 /+}$ myocytes contain lower levels of $\mathrm{Ca}^{2+}$ than do the SRs of wild-type myocytes (Figures 1 and 2).

Because $\alpha M H C^{403 /+}$ myocyte SRs contained reduced amounts of $\mathrm{Ca}^{2+}$, we hypothesized that $\mathrm{SR} \mathrm{Ca}^{2+}$ storage proteins would correspondingly be diminished. Decreased levels of calsequestrin and RyR2 in the SRs of $\alpha M H C^{403 /+}$ myocytes were found. Calsequestrin is a $55-\mathrm{kDa}$ highcapacity $\mathrm{Ca}^{2+}$-binding protein that both serves as a reservoir for $\mathrm{SR} \mathrm{Ca}^{2+}$ and, with junctin and triadin, forms a complex that regulates $\mathrm{Ca}^{2+}$ release via RyR2 $(26,28,29)$. Downregulation of calsequestrin and the other components of this quaternary RyR 2 complex in $\alpha M H C^{403 /+}$ myocytes is consistent with decreased SR Ca ${ }^{2+}$ levels. SR $\mathrm{Ca}^{2+}$ levels may further be depleted by increased phosphorylation of the RyR2 channel in $\alpha M H C^{403 /+}$ myocytes. Phosphorylation decreases the amount of RyR2-associated FKBP12.6, which makes the channel more sensitive to calcium-induced activation and increases the probability of channel opening $(21,30,31)$. Whereas only one of three potential sites was phosphorylated in wild-type myocytes, most RyR2 channels from $\alpha M H C^{403 /+}$ myocytes had two or more phosphorylated sites.

Reduced SR $\mathrm{Ca}^{2+}$ levels but normal cytosolic $\mathrm{Ca}^{2+}$ levels in $\alpha M H C^{403 /+}$ myocytes are consistent with the model that the mutant sarcomere functions like an ion trap (Figure 5). Altered biophysical properties of a mutated myosin heavy chain could enhance $\mathrm{Ca}^{2+}$ retention by the sarcomere and deplete $\mathrm{SR} \mathrm{Ca}^{2+}$ stores. Observations of $\alpha M H C^{403 /+}$ muscle physiology support this model: mutant fibers show greater-than-normal isometric tension development at submaximal $\mathrm{Ca}^{2+}$ levels, and mutant hearts exhibit decreased rates of relaxation $(15,32)$.

The development of SR $\mathrm{Ca}^{2+}$ dysregulation follows mutant peptide expression and predates the hypertrophic response in $\alpha M H C^{403 /+}$ mice. By 4 weeks after birth, when $\alpha M H C^{403 /+}$ myocytes express equal amounts of mutant and wild-type peptide (24), dysregulation of SR calcium was apparent, and if it went uninterrupted, phenotypic manifestations of hypertrophic cardiomy- opathy ensued $(13,14)$. L-type channel inhibition by diltiazem most likely interrupts this process by chronic attenuation of calcium-induced $\mathrm{SR} \mathrm{Ca}^{2+}$ release, so as to limit $\mathrm{Ca}^{2+}$ sequestration by the mutant sarcomere. The concurrent restoration of normal RyR2 and SR $\mathrm{Ca}^{2+}$ binding proteins levels and reduction of cardiac hypertrophy and fibrosis in diltiazem-treated $\alpha M H C^{403 /+}$ mice further support a mechanistic link between $\mathrm{SR} \mathrm{Ca}^{2+}$ dysregulation and disease phenotype.

The L-type $\mathrm{Ca}^{2+}$ channel is the primary target of diltiazem. However, diltiazem is known to have other cellular targets, such as the mitochondrial $\mathrm{Na}^{+} / \mathrm{Ca}^{2+}$ exchanger. Alteration in mitochondrial $\mathrm{Ca}^{2+}$ concentration might change $\alpha M H C^{403 /+}$ myocyte energetics and thereby alter the hypertrophic response of the heart. Diltiazem might reduce the hypertrophic response by improving cardiac energetics. However, under normal conditions, diltiazem-treated $\alpha M H C^{403 /+}$ hearts appear to do less work (lower heart rate, reduced stiffness [EES], and reduced $\mathrm{dP} / \mathrm{dt}_{\max }$; see Table 1) than the untreated

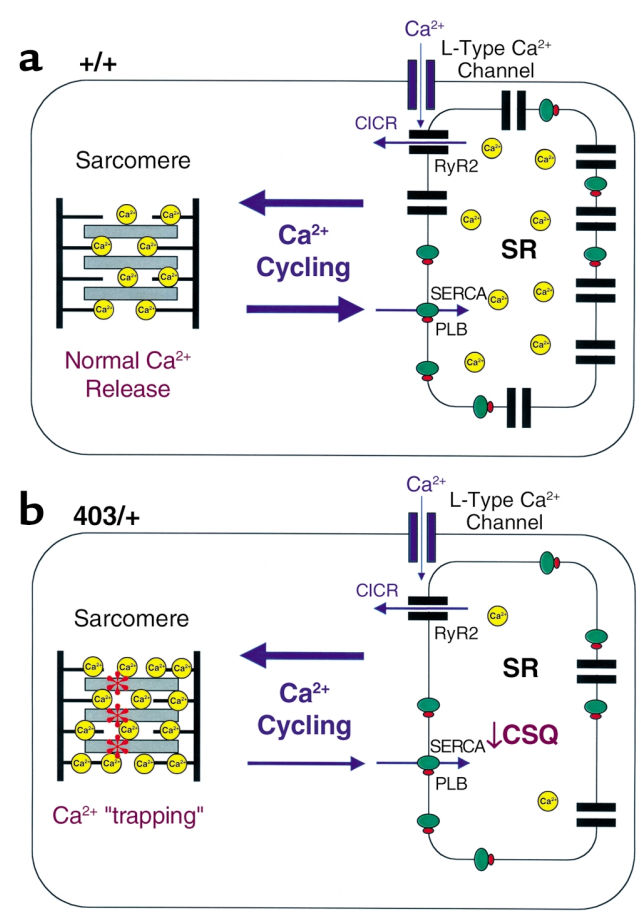

\section{Figure 5}

Model of $\mathrm{Ca}^{2+}$ cycling in cardiac myocytes and the effects of a hypertrophic cardiomyopathy-causing mutation. (a) Wild-type myocytes showing normal $\mathrm{Ca}^{2+}$ regulation. $\mathrm{Ca}^{2+}$ enters the myocyte through L-type $\mathrm{Ca}^{2+}$ channels. Small entry of $\mathrm{Ca}^{2+}$ stimulates Ca release (calcium-induced $\mathrm{Ca}^{2+}$ release; $\mathrm{CICR}$ ) from the $\mathrm{SR}$ via cardiac ryanodine receptors (RyR2) to the sarcomere. $\mathrm{Ca}^{2+}$ returns to the $\mathrm{SR}$ via the sarcoplasmic/endoplasmic $\mathrm{Ca}^{2+}$ ATPase (SERCA) pump, which is regulated by phospholamban (PLB). $\mathrm{Ca}^{2+}$ cycling is "balanced" between the sarcomere and SR. (b) Mutant $\left(\alpha M H C^{403 /+}\right)$ myocytes have a mutation in the sarcomere (represented by an asterisk). The defective sarcomere acts as an ion trap, resulting in accumulation of $\mathrm{Ca}^{2+}$. Less $\mathrm{Ca}^{2+}$ returns to the $\mathrm{SR}$, resulting in decreased $\mathrm{SR} \mathrm{Ca}^{2+}$ stores, decreased SR calsequestrin (CSQ), and reduced expression of RyR2. The net effect is a $\mathrm{Ca}^{2+}$ shift within the cell, with a relative $\mathrm{Ca}^{2+}$ excess in the sarcomere, and $\mathrm{Ca}^{2+}$ depletion in the SR. 
$\alpha M H C^{403 /+}$ heart, suggesting that even if cardiac energetics remain unaltered in $\alpha M H C^{403 /+}$ hearts, the hearts should benefit from diltiazem-mediated work reduction.

Other investigators have identified several important intracellular $\mathrm{Ca}^{2+}$ sensors that can activate several signaling pathways to effect myocyte growth and function (for review, see ref. 33). Based on its association with the SR and function in RyR2 channel phosphorylation, calci$\mathrm{um} /$ calmodulin-dependent protein kinase (CamKII) is a particularly intriguing candidate for signaling myocyte growth (34). Levels of two well-characterized signaling molecules, calmodulin and the calcium/calmodulin-activated phosphatase calcineurin (PP2B-A $\alpha$ and $-\mathrm{A} \beta$ ), were not altered in $\alpha M H C^{403 /+}$ mice (data not shown). Whether transient or compartmentalized changes in these or $\mathrm{Ca}^{2+}$ activation of other signaling molecules triggers hypertrophy in $\alpha M H C^{403 /+}$ mice remains unknown.

An important conclusion from these data is that early restoration of $\mathrm{SR} \mathrm{Ca}^{2+}$ decreases the hypertrophic response to a sarcomere mutation. Administration of diltiazem, in doses resulting in only modest hemodynamic effects, to prehypertrophic $\alpha M H C^{403 /+}$ mice improved cardiac function and provided long-term (39 weeks) attenuation of hypertrophic pathology. Improvement in cardiac function was almost exclusively in systolic function parameters, with little effect on diastolic function (Table 1). This may suggest that altering $\mathrm{Ca}^{2+}$ handling is important for contractile function, but that diastolic function is mediated by alternate mechanisms. In humans with clinical evidence of hypertrophic cardiomyopathy, L-type $\mathrm{Ca}^{2+}$ channel inhibitors such as diltiazem are used to treat symptoms. Our findings indicate that greater benefit should occur if these inhibitors are administered in advance of disease expression. In conjunction with gene-based, preclinical diagnosis of human sarcomere protein mutations, evaluation of the potential for diltiazem, and other pharmacologic agents that restore $\mathrm{SR} \mathrm{Ca}^{2+}$ levels, to inhibit development of hypertrophic cardiomyopathy appears warranted.

\section{Acknowledgments}

We thank Larry R. Jones for providing the RyR2 and junctin antibodies, and Julie Zhang for myocyte isolation. The Howard Hughes Medical Institute supported these studies. C. Semsarian is the recipient of a National Heart Foundation of Australia grant. U. Mende is supported by an NIH Specialized Centers of Research grant and an American Heart Association Scientist Development grant. I. Ahmad is supported by a Sarnoff Fellowship.

1. Fatkin, D., Seidman, J.G., and Seidman, C.E. 2000. Hypertrophic cardiomyopathy. In Cardiovascular medicine. J.T. Willerson and J.N. Cohn, editors. W.B. Saunders Co. Philadelphia, Pennsylvania, USA. 1055-1074.

2. Seidman, C.E., and Seidman, J.G. 2001. Hypertrophic cardiomyopathy. In The metabolic and molecular bases of inherited disease. C.R. Scriver, A.L. Beaudet, W.S. Sly, and D. Valle, editors. McGraw-Hill. New York, New York, USA. 5433-5452.

3. Maron, B.J., Bonow, R.O., Cannon, R.O., III, Leon, M.B., and Epstein, S.E 1987. Hypertrophic cardiomyopathy. Interrelations of clinical manifestations, pathophysiology, and therapy (1). N. Engl.J. Med. 316:844-852.

4. Spirito, P., Seidman, C.E., McKenna, W.J., and Maron, B.J. 1997. The management of hypertrophic cardiomyopathy. N. Engl. J. Med. 336:775-785.

5. Maron, B.J., Epstein, S.E., and Roberts, W.C. 1986. Causes of sudden death in competitive athletes. J. Am. Coll. Cardiol. 7:204-214.

6. Maron, B.J., et al. 1996. Sudden death in young competitive athletes. Clinical, demographic, and pathological profiles. JAMA. 276:199-204.

7. Vikstrom, K.L., Factor, S.M., and Leinwand, L.A. 1996. Mice expressing mutant myosin heavy chains are a model for familial hypertrophic cardiomyopathy. Mol. Med. 2:556-567.

8. Kittleson, M.D., et al. 1999. Familial hypertrophic cardiomyopathy in maine coon cats: an animal model of human disease. Circulation. 99:3172-3180.

9. Marian, A.J., et al. 1999. A transgenic rabbit model for human hypertrophic cardiomyopathy. J. Clin. Invest. 104:1683-1692.

10. Oberst, L., et al. 1998. Dominant-negative effect of a mutant cardiac troponin $\mathrm{T}$ on cardiac structure and function in transgenic mice. J. Clin. Invest. 102:1498-1505.

11. Patel, R., et al. 2001. Simvastatin induces regression of cardiac hypertrophy and fibrosis and improves cardiac function in a transgenic rabbit model of human hypertrophic cardiomyopathy. Circulation. 104:317-324.

12. Lim, D.S., et al. 2001. Angiotensin II blockade reverses myocardial fibrosis in a transgenic mouse model of human hypertrophic cardiomyopathy. Circulation. 103:789-791.

13. Geisterfer-Lowrance, A.A., et al. 1996. A mouse model of familial hypertrophic cardiomyopathy. Science. 272:731-734.

14. McConnell, B.K., et al. 2001. Comparison of two murine models of familial hypertrophic cardiomyopathy. Circ. Res. 88:383-389.

15. Blanchard, E., Seidman, C., Seidman, J.G., LeWinter, M., and Maughan, D 1999. Altered crossbridge kinetics in the $\alpha M H C^{403 /+}$ mouse model of familial hypertrophic cardiomyopathy. Circ. Res. 84:475-483.

16. Fatkin, D., et al. 2000. An abnormal Ca2+ response in mutant sarcomere protein-mediated familial hypertrophic cardiomyopathy. J. Clin. Invest. 106:1351-1359.

17. Bers, D.M. 2000. Calcium fluxes involved in control of cardiac myocyte contraction. Circ. Res. 87:275-281.

18. Kim, S.J., et al. 1999. An $\alpha$-cardiac myosin heavy chain gene mutation impairs contraction and relaxation function of cardiac myocytes. Am. J. Physiol. 276:H1780-H1787.

19. McConnell, B.K., Moravec, C.S., and Bond, M. 1998. Troponin I phosphorylation and myofilament calcium sensitivity during decompensated cardiac hypertrophy. Am. J. Physiol. 274:H385-H396.

20. McConnell, B.K., et al. 1999. Dilated cardiomyopathy in homozygous myosin-binding protein-C mutant mice. J. Clin. Invest. 104:1235-1244.

21. Marx, S.O., et al. 2000. PKA phosphorylation dissociates FKBP12.6 from the calcium release channel (ryanodine receptor): defective regulation in failing hearts. Cell. 101:365-376.

22. Georgakopoulos, D., et al. 1999. The pathogenesis of familial hypertrophic cardiomyopathy: early and evolving effects from an $\alpha$-cardiac myosin heavy chain missense mutation. Nat. Med. 5:327-330.

23. Palmer, B.M., Lynch, J.M., Snyder, S.M., and Moore, R.L. 2001. Renal hypertension prevents run training modification of cardiomyocyte diastolic Ca2+ regulation in male rats. J. Appl. Physiol. 90:2063-2069.

24. Fatkin, D., et al. 1999. Neonatal cardiomyopathy in mice homozygous for the Arg403Gln mutation in the $\alpha$-cardiac myosin heavy chain gene. J. Clin. Invest. 103:147-153.

25. Semsarian, C., et al. 2001. A polymorphic modifier gene alters the hypertrophic response in a murine model of familial hypertrophic cardiomyopathy. J. Mol. Cell. Cardiol. 33:2055-2060.

26. Zhang, L., Kelley, J., Schmeisser, G., Kobayashi, Y.M., and Jones, L.R. 1997. Complex formation between junctin, triadin, calsequestrin, and the ryanodine receptor. Proteins of the cardiac junctional sarcoplasmic reticulum membrane. J. Biol. Chem. 272:23389-23397.

27. Scriven, D.R., Dan, P., and Moore, E.D. 2000. Distribution of proteins implicated in excitation-contraction coupling in rat ventricular myocytes. Biophys. J. 79:2682-2691.

28. Jones, L.R., et al. 1998. Regulation of Ca2+ signaling in transgenic mouse cardiac myocytes overexpressing calsequestrin. J. Clin. Invest. 101:1385-1393.

29. Niki, I., Yokokura, H., Sudo, T., Kato, M., and Hidaka, H. 1996. Ca2+ signaling and intracellular $\mathrm{Ca} 2+$ binding proteins. J. Biochem. (Tokyo). 120:685-698.

30. Szegedi, C., Sarkozi, S., Herzog, A., Jona, I., and Varsanyi, M. 1999. Calsequestrin: more than 'only' a luminal $\mathrm{Ca} 2+$ buffer inside the sarcoplasmic reticulum. Biochem. J. 337:19-22.

31. Yano, K., and Zarain-Herzberg, A. 1994. Sarcoplasmic reticulum calsequestrins: structural and functional properties. Mol. Cell. Biochem. 135:61-70.

32. Spindler, M., et al. 1998. Diastolic dysfunction and altered energetics in the $\alpha M H C^{403 /+}$ mouse model of familial hypertrophic cardiomyopathy. J. Clin. Invest. 101:1775-1783.

33. Frey, N., McKinsey, T.A., and Olson, E.N. 2000. Decoding calcium signals involved in cardiac growth and function. Nat. Med. 6:1221-1227.

34. Passier, R., et al. 2000. CaM kinase signaling induces cardiac hypertrophy and activates the MEF2 transcription factor in vivo. J. Clin. Invest. 105:1395-1406. 